\title{
Estimation of roe deer density based on the abundance and rate of disappearance of their faeces from the forest
}

\author{
Władysław AULAK and Joanna BABIŃSKA-WERKA
}

\begin{abstract}
Aulak W. and Babińska-Werka J. 1990. Estimation of roe deer density based on the abundance and rate of disappearance of their faeces from the forest. Acta theriol. 35: $111-120$.

Population density of roe deer Capreolus capreolus (Linnaeus, 1758) was assessed in a small forest (about 200 ha) surrounded with fields. The method used was based on known amounts of roe deer faeces in the forest and their rate of disappearance. Faeces disappearance was exponential, and the average time of their persistence on the forest floor was 26 days in summer, 70 in spring, and 118 in autumn. The faeces disappearance rate was significantly affected by weather conditions (air temperature, amount of rainfall, number of rainy days), as well as by the activity of coprophages. Estimations of roe deer density by driving the animals about the forest, and by assessing the quantity of faeces gave similar results.

Warsaw Agricultural University, Department of Game Management, Rakowiecka 26/30, $02-528$ Warszawa, Poland
\end{abstract}

Key words: density, Capreolus capreolus, feaces decay

\section{Introduction}

The faeces of large ungulates, including the roe deer Capreolus capreolus (Linnaeus, 1758), can persist a long time on the forest floor. On the basis of their presence it is possible to determine the penetration of habitats and seasonal use of a study area by these animals (Riney 1957, Julander et al. 1963, Collins and Urness 1981, Aulak and Babińska-Werka 1990), as well as the relative population size of roe deer and their diet (Eberhart and Van Etten 1956, Wallmo et al. 1962, Zyzner and Urness 1968, Helle 1980).

To be able to estimate the population size from faeces it is necessary to establish the disappearance rate of faeces and their quantity in a study area. This method makes it possible to asses the size of a roe deer population in any area we are interested in. This is particularly important when there are not enough people to census the animals by herding (Aulak and Goszczyński 1986). The faeces existance time may depend on many factors, both abiotic and biotic. There has been little information in the literature on the faeces disappearance rate of the ungulates in a habitat. With limited data at his disposal, Dzięciołowski (1976) estimated the red deer faeces persistance time as being 2 months in summer, and 3 in winter. In their studies on the decomposition rate of the faeces of ungulates, Gusev and Guseva (1983) jointly treated their data concerning the elk, wild boar and roe deer. According to them, $50 \%$ of faeces decomposed within 3 months, and the remainder within 3 years. Mitchell 


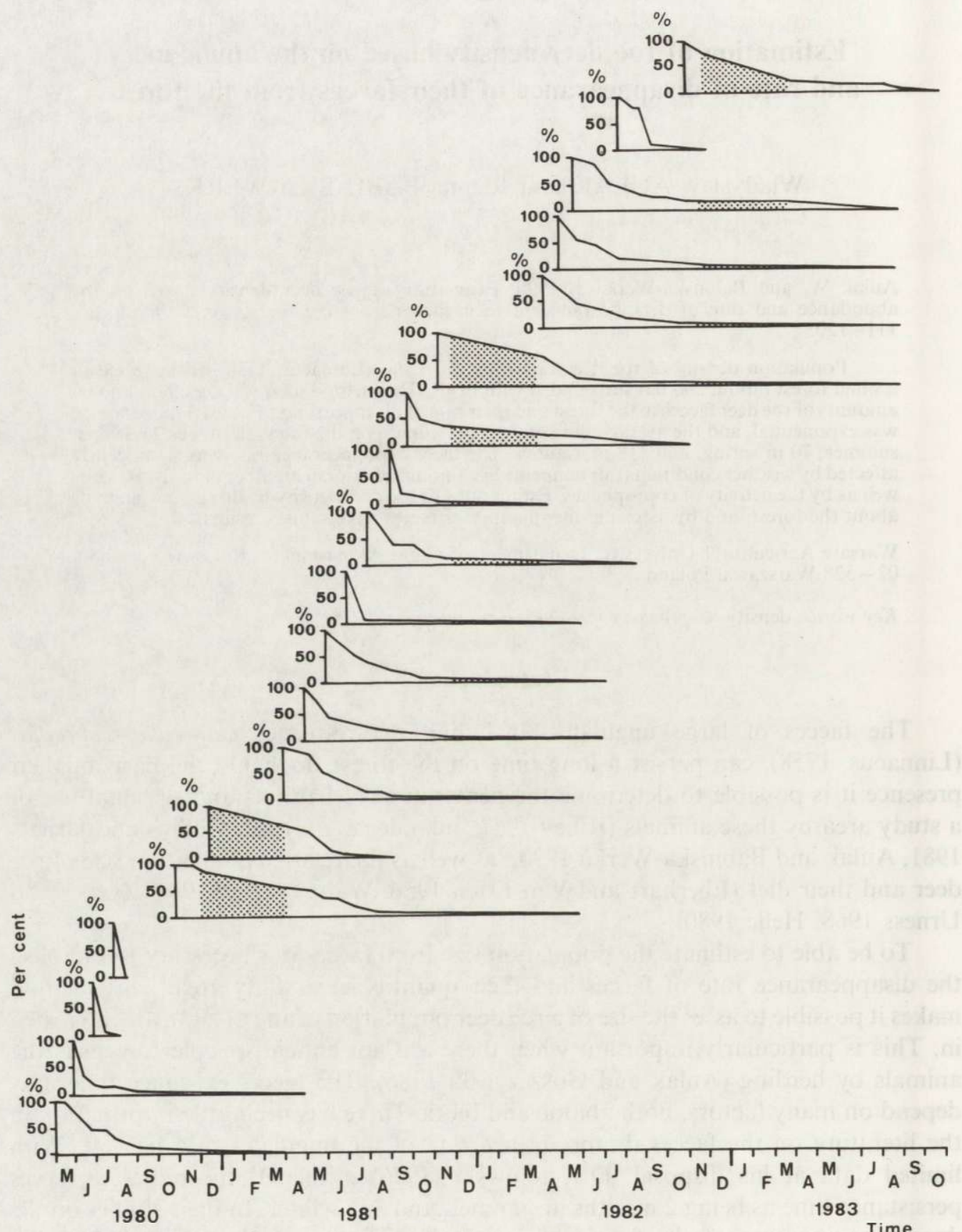

Fig. I. Rate of disappearance of roe deer pellets exposed in different seasons, expressed as a percentage of the initial number of pellets. Dotted areas indicate winter period (October-March). 
et al. (1985) estimated the average faeces disappearance time for the roe deer as being $3-5$ months. There is therefore a lack of accuracy in the data.

The aim of this study was to determine the numbers of the roe deer on the basis of the disappearance rate of their faeces and known quantities of excrements accumulated on the forest floor.

\section{Study area and methods}

The studies were carried out in a forest owned by the Rogów Experimental Station of Forest Department of Warsaw Agricultural University, located in the central part of Poland $\left(51^{\circ} 48^{\prime} \mathrm{N}, 19^{\circ} 53^{\prime} \mathrm{E}\right)$. The size of the forest was about 200 ha. The following forest habitat types were found there: a mixed fresh coniferous forest - MFCF (Pino-Quercetum typicum Kozł. 1925), mixed fresh deciduous forest-MFDF (Tilio-Carpinetum calamagrostietosum Traczyk, 1962) and a fresh deciduous forest-FDF (Tilio-Carpinetum typicum Traczyk, 1962). The first two habitat types dominated. The proportions of stand-age classes varied, but stands aged up to 40 years prevailed $(70 \%)$. There were no stands aged over 80 years in the area studied. Regardless of the habitat type, the dominant species was the Scots pine (Pinus silvestris L.). All the stands had been planted. A detailed description of the ground-layer and understorey vegetation can be found in Aulak's paper (in print).

The studies were carried out from 1980 to 1983. In that period the roe deer population, according to the data from a census carried out by herding in spring, ranged from 89 to 124 head, which corresponded to a density of 45 to nearly 62 head per 100 ha (W. Aulak and J. Babińska-Werka, in prep.).

Since the proportion of fresh deciduous forest (FDF) habitats was small, experiments were conducted only in the other two habitats. In each of them a study plot was selected in every stand-age class ( 20 year classes), which gave a total of 8 study plots. In each study plot three wooden frames 15 by $15 \mathrm{~cm}$ were placed on the forest floor. At the beginning of every month a sample of 20-newly defecated roe deer pellets was placed in each frame. The samples were thereafter checked for quantity every 2 weeks. In several cases no samples were put in the frames, because no newly-defecated pellets could be found in the forest. During every check only those pellets were recorded which had survived in their natural shape in a frame. Pellets were not placed in frames nor their quantity checked during the winter.

In most cases it was difficult to establish the cause of pellet disappearance. Very often the soil within a frame appeared to have been scarified, which indicated that the pellets had been pulled into coprophages' tunnels. In some cases pellets were partly broken up and disintegrated, which indicated a decomposition process under the influence of abiotic factors, probably with the contribution of microorganisms. In most cases only reduced numbers of pellets were found between two successive checking dates. With the biotic factor clearly predominating over the abiotic one in the pellet-disappearance rate, it has been assumed that the main factor responsible for the loss was coprophage activity. For this reason, it has been decided that the term pellet "disappearance" rather than pellet "decomposition" should be used.

In the period 1980-1982, 19 series of pellet samples were placed on the forest floor. In 1983, sample placing was stopped, but the quantity check on the series placed during the preceding years was not terminated until all of them had disappeared.

To determine the roe deer faeces density at a particular date in the forest under research, roe deer pellet samples were collected in 900 sample circles $\left(1 \mathrm{~m}^{2}\right.$ each) randomly distributed in all the forest habitat types and age stands (Aulak and Babińska-Werka 1990).

\section{Results}

Faeces-disappearance rate

The disappearance rate of faeces was calculated from the persistence curve of pellets placed in the forest (Fig. 1). The curve was most often exponential in nature, as 
indicated by the comparison of the correlation coefficients for particular samples, assuming a rectilinear and an exponential regression (Table 1). In 14 of 17 series analysed the correlation coefficient was higher in the case of an exponential curve than in the case of a rectilinear function.

Though the curves varied considerably (Fig. 1), certain regularities have been noticed in the faeces disappearance rate. In series placed in the forest immediately before the winter the amount lost during winter was small. Pellets placed in the forest in the autumn persisted on the forest floor much longer than faeces exposed in other seasons.

The disappearance rate of the spring faeces series (on an average within 70 days), and especially that of the summer samples (on an average within 28 days), were fast (Table 2). Faeces placed on the forest floor in the autumn continued to exist there the longest time (on an average 118 days). In many cases a small number of pellets of each series persisted in the frames for a long time, due to which the terminal flat portion of the

Table 2. Mean time of roe deer faeces persisting in the forest (in days).

\begin{tabular}{lllr}
\hline $\begin{array}{c}\text { Initial dates } \\
\text { of experiments }\end{array}$ & Spring & Summer & Autumn \\
\hline 1980, May 03 & $68.9 \pm 6.2$ & & \\
1980, June 04 & $23.5 \pm 4.8$ & $8.1 \pm 1.4$ & \\
1980, June 30 & & $6.5 \pm 0.0$ & \\
1980, Aug. 02 & & & $166.4 \pm 12.5$ \\
1980, Nov. 03 & & & \\
1980, Dec. 12 & & & \\
1981, Apr. 06 & $88.5 \pm 8.9$ & & \\
1981, Apr. 28 & $78.3 \pm 10.3$ & & \\
1981, June 02 & $68.4 \pm 6.8$ & $18.8 \pm 2.8$ & \\
1981, June 25 & & $67.9 \pm 10.0$ & \\
1981, Aug. 04 & & & \\
1981, Sept. 03 & & & \\
1981, Sept. 30 & & & \\
1981, Nov. 14 & & & \\
1982, Apr. 18 & $65.2 \pm 10.3 \pm 15.2$ \\
1982, May 08 & $73.7 \pm 11.8$ & & 119.3 \\
1982, May 29 & $93.5 \pm 13.4$ & $36.3 \pm 3.3$ & \\
1982, Aug. 05 & & & $117.6 \pm 19.8$ \\
1982, Nov. 07 & & & \\
Mean & $70.0 \pm 7.0$ & $26.5 \pm 8.5$ & 11.3 .2 \\
\hline
\end{tabular}

Table 1. Comparison of correlation coefficients for the rates of disappearance of the roe deer pellets expressed as linear regression and exponential function.

\begin{tabular}{lcc}
\hline $\begin{array}{c}\text { Initial dates } \\
\text { of experiments }\end{array}$ & \multicolumn{2}{c}{ Correlation coefficient } \\
\cline { 2 - 3 } & $\begin{array}{c}\text { Linear } \\
\text { regression }\end{array}$ & $\begin{array}{c}\text { Exponential } \\
\text { function }\end{array}$ \\
\hline 1980, May 03 & -0.8377 & -0.9058 \\
1980, June 04 & -0.5611 & -0.9518 \\
1980, Nov. 03 & -0.8779 & -0.8687 \\
1980, Dec. 12 & -0.9660 & -0.8578 \\
1981, Apr. 06 & -0.7780 & -0.8868 \\
1981, Apr. 28 & -0.7765 & -0.6647 \\
1981, June 02 & -0.7724 & -0.6628 \\
1981, June 25 & -0.4091 & -0.8896 \\
1981, Aug. 04 & -0.8297 & -0.5676 \\
1981, Sept. 03 & -0.5656 & -0.6658 \\
1981, Sept. 30 & -0.9220 & -0.5647 \\
1981, Nov. 14 & -0.6709 & -0.9123 \\
1982, Apr. 18 & -0.6279 & -0.5386 \\
1982, May 08 & -0.6992 & -0.9839 \\
1982, May 29 & -0.7739 & -0.5638 \\
1982, Aug. 05 & -0.8463 & -0.8252 \\
1982, Nov. 07 & -0.9382 & -0.6641 \\
Total & -0.6625 & -0.8809 \\
\hline
\end{tabular}


Table 3. Mean time (in days) of roe deer faeces persisting in different habitats. MFCF - mixed fresh coniferous forest, MFDF - mixed fresh deciduous forest.

\begin{tabular}{lrlr}
\hline $\begin{array}{c}\text { Initial dates } \\
\text { of experiments }\end{array}$ & MFCF & & MFDF \\
\hline 1980, May 03 & 80.1 & $>$ & 57.6 \\
1980, June 04 & 34.0 & $>$ & 13.8 \\
1980, June 30 & 8.1 & $>$ & 8.0 \\
1980, Aug. 02 & 6.5 & $=$ & 6.5 \\
1980, Nov. 03 & 186.0 & $>$ & 135.9 \\
1980, Dec. 12 & 114.1 & $<$ & 122.3 \\
1981, Apr. 06 & 114.0 & $<$ & 70.6 \\
1981, Apr. 28 & 82.5 & $>$ & 74.3 \\
1981, June 02 & 70.5 & $>$ & 57.8 \\
1981, June 25 & 16.6 & $<$ & 20.8 \\
1981, Sept. 30 & 133.8 & $>$ & 71.2 \\
1981, Nov. 14 & 154.6 & $>$ & 141.0 \\
1982, Apr. 18 & 112.4 & $>$ & 30.6 \\
1982, May 08 & 98.3 & $>$ & 49.8 \\
1982, May 29 & 48.6 & $<$ & 124.2 \\
1982, Nov. 07 & 126.7 & $>$ & 110.9 \\
\hline
\end{tabular}

curve was longer.

The mean time of faeces persistence in the mixed deciduous forest and in the mixed coniferous forest was compared ( $\mathrm{Ta}$ ble 3 ). In most cases (12 out of 16 series) the faeces persistance time in the poorer habitat (mixed coniferous forest) was longer.

In statistical tests for the success fraction the number of cases of faster pellet disappearance in the mixed deciduous forest ( $75 \%$ of all samples) appeared to be significantly higher at $p<0.05$ than in those for which disappearance was assumed to be independent of the habitat $(50 \%$ of samples). Thus, the trend of a longer pellet persistence in the poorer habitat (mixed coniferous forest) appeared to be significant.

\section{Relationship between faeces disappearance and weather conditions}

Tests were carried out to check the relationship between the faeces disappearance rate and weather conditions significant to pellet decomposition [mean daily air temperature $\left({ }^{\circ} \mathrm{C}\right)$ measured $2 \mathrm{~m}$ above the ground, total rainfall $(\mathrm{mm})$, and number of rainy days] (Table 4$)$.

Of a total of 19 pellet series exposed in only 6 cases was a statistically significant correlation found between the faeces disappearance rate and the particular meteorological parameters (Table 4). This seems to confirm the statement that the effect of coprophage activity on the rate of pellet disappearance was more significant.

Table 4. Correlation between the numbers of roe deer pellets disappearing in a given experiment and the weather conditions. Rho - Spearman rank correlation coefficient.

\begin{tabular}{ccl}
\hline $\begin{array}{c}\text { Initial date } \\
\text { of experiments }\end{array}$ & Rho & \multicolumn{1}{c}{ Factor } \\
\hline 1980, May 03 $030.6036^{2}$ & rainfall $(\mathrm{mm})$ \\
1980, June 04 & $0.7923^{1}$ & temperature $\left({ }^{\circ} \mathrm{C}\right)$ \\
1980, June 04 & $0.9000^{1}$ & rainfall $(\mathrm{mm})$ \\
1980, Sept. 30 & $0.5456^{3}$ & number of days with rain \\
1982, May 09 & $0.4982^{3}$ & number of days with rain \\
1982, Aug. 05 & $0.9940^{1}$ & temperature $\left({ }^{\circ} \mathrm{C}\right)$ \\
\hline${ }^{1} p<0.01,{ }^{2} p<0.02,{ }^{3} p<0.05$. & \\
\hline
\end{tabular}




\section{Determination of roe deer population size on the basis of faeces analyses}

To determine the size of a roe deer population from the total amount of faeces, the quantity of faeces defecated by the whole population during 24 hours must be divided by the average quantity of faeces defecated by 1 individual. An evaluation is possible on the basis of known amounts of faeces accumulated in the forest and their disappearance rate.

The faeces accumulated in the forest came from the last 24 hours and preceding periods. Test samples for faeces disappearance were placed in the forest on specified days: M1, M2, M3 etc. (Fig. 2). They represented certain time intervals: T1, T2, T3 etc. Only a certain percentage of pellets of each series persisted till the day of assessment of the roe deer population size: $\mathrm{P} 1, \mathrm{P} 2, \mathrm{P} 3$ etc. It has been assumed to be representative of the respective time intervals $(\mathrm{T})$.

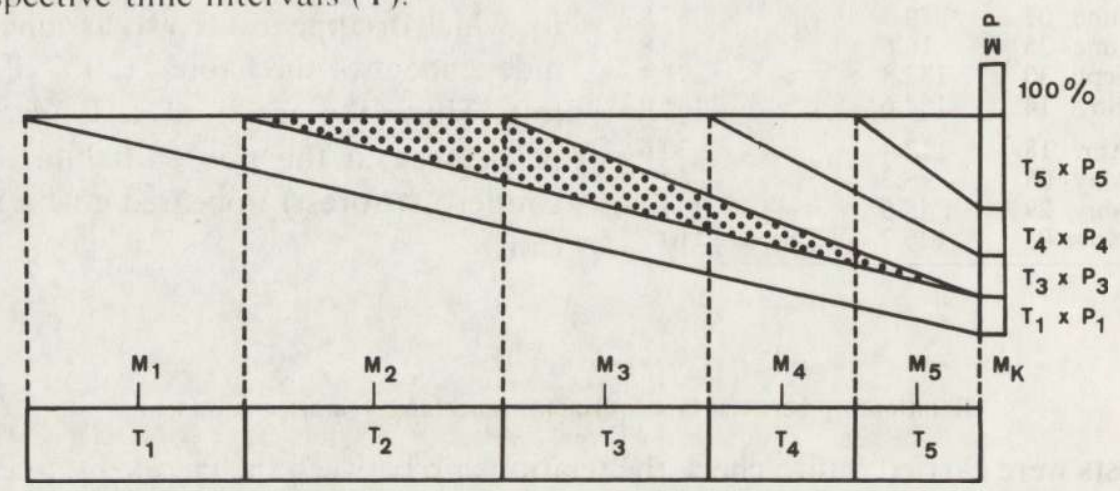

Fig. 2. Scheme of calculation of the daily portion of pellets defecated by the roe deer population, based on one-time pellet collection in the whole forest, and on data of pellet disappearance rate.

$\mathrm{M}_{1}, \mathrm{M}_{2}, \ldots . . \mathrm{M}_{5}-$ moments of pellet series exposure for faeces disappearance rate analysis,

$\mathrm{M}_{\mathrm{k}} \quad$ - day of roe deer population density estimation,

$\mathrm{T}_{1}, \mathrm{~T}_{2}, \ldots . \mathrm{T}_{5}$ - time interval represented by individual pellet series,

$\mathrm{P}_{1}, \mathrm{P}_{2}, \ldots . . \mathrm{P}_{5} \quad$ - pellet percentage in each series, which persisted till the day of roe deer abundance estimation $\left(\mathrm{M}_{\mathrm{k}}\right)$,

SP - number of roe deer pellets on day $M_{k}$, expressed in relative units $(T \times P)$.

Dotted area denotes the period $\left(\mathrm{T}_{2}\right)$, from which no pellets persisted till the calculation days $\left(\mathrm{M}_{\mathrm{k}}\right)$.

The total of pellets $(\Sigma \mathrm{P})$ on a particular day therefore represented $100 \%$ of the faeces defecated during the last 24 hours plus the total of faeces from preceding periods: T1P1, T2P2, T3P3 etc.

$$
\Sigma \mathrm{P}=100 \%+\Sigma \mathrm{TP}
$$

So the proportion of faeces of the last 24 hours $(\mathrm{K})$ was equal to:

$$
\mathrm{K}=100 \% / \Sigma \mathrm{P} \%
$$

The total quantity of faeces in the forest, expressed as the number of pellets, was converted to mass $(\mathrm{M})$ by multiplying that number by the average weight of one pellet from the last 24 hours, that is, not old, and not leached.

The total mass of faeces from the last 24 hours was equal to: $\mathrm{D}=\mathrm{M} \times \mathrm{K}$. Divided 
Table 5. Parameters used to estimate the number of roe deer present in the forest in April, 1982. T - length of time intervals represented by the pellet series exposed, $\mathbf{P}$ - percentage of faeces which persisted till the evaluation day.

\begin{tabular}{ccr}
\hline T (days) & $\mathrm{P}(\%)$ & $\mathrm{T} \times \mathrm{P}$ \\
\hline 50 & 0.8 & 40.0 \\
66 & 1.3 & 85.8 \\
29 & 4.3 & 124.7 \\
31 & 4.3 & 133.3 \\
31 & 1.0 & 31.0 \\
35 & 8.9 & 311.5 \\
35 & 22.0 & 770.0 \\
100 & 53.7 & 5370.0 \\
Total & & 6866.3 \\
\hline
\end{tabular}

by the average daily ( 24 hours) weight of faeces defecated by one roe deer (d) this value gives the number of roe deer $(\mathrm{N}): \mathrm{N}=\mathrm{D} / \mathrm{d}$.

It happened sometimes that pellets of a control series failed to persist till the day of roe deer population size calculation. Data from such a series were not included in the calculation. A situation of this kind occurred in the series of samples placed at date M2 (Fig. 2).

As an example, roe deer numbers have been calculated for 18 April, 1982. The total of pellets on the forest floor came from 378 days, and pellet disappearance was represented by 8 pellet series placed in the forest for faeces disappearance rate analyses (Table 5).

$$
\begin{aligned}
P= & 100 \%+6866.3 \%=6966.3 \% \\
K= & 100 / 6966.3=0.01435 \\
M= & 1390.32 \mathrm{~kg} \text { d.w. }=\text { pellet mass in the forest assessed } \\
& \text { on } 18 \text { April, } 1982 \text { on the basis of } 900 \text { circle samples. }
\end{aligned}
$$

$\mathrm{D}=\mathrm{M} \times \mathrm{K}=1390.32 \times 0.01435=19.95 \mathrm{~kg}$ d.w.

The quantity defecated by one roe deer, expressed in dry weight units, adopted after Dróżdż and Osiecki (1973), was $0.235 \mathrm{~kg}$.

Estimated number of roe deer was:

$$
\mathrm{N}=19.95: 0.235=84.9
$$

\section{Discussion}

The faeces disappearance rate determined in the present study was of an exponential nature, that is, in the successive periods following defecation the rate of disappearance was proportional to the current quantity of faeces. Only in certain periods, under extreme weather conditions, was the rate accelerated or slowed down. Maybe the weather conditions throughout the period between defecation and faeces disappearance influenced the disappearance rate, but the number of observations was too small to reveal such a relationship.

The data provided by the present study concerning the disappearance of roe deer faeces agree with those reported by Mitchell et al. (1985), and Gusev and Guseva (1983) who also found a higher faeces disappearance rate in summer that in autumn and winter.

Faeces deposited during the latter seasons can persist in the habitat for over a year. According to Wigley and Johnson (1981), red deer faeces decomposition is correlated with the amount of rainfall and wind velocity.

According to Dzięciołowski (1976), the persistence time of red deer faeces is 2 months in summer, and 3 months in winter. Our results indicate a longer persistence 
time of the faeces of roe deer in the forest. The method used in this study seems more reliable because it comprised several control sample series placed in different seasons over a 3-year study cycle.

In late spring and summer in pellet samples, whose disappearance was the fastest, pellet crumbling was very seldom observed, whereas signs of coprophage activity were very frequent. The most common coprophage species in the forest was the beetle Geotrupes stercorosus whose density in summer is high (Sandner 1976). Most attractive to it are the faeces of large mammals (Borowski 1960). In the forest under study beetles occurred in fairly large numbers, as indicated by the fact that 5 and up to 10 beetles were found on a faeces sample. It seems justifiable to regard beetles to be the main cause of roe deer pellet disappearance, which has been confirmed by the literature (Borowski 1960, Breymeyer 1974, Nakamura 1975, Sandner 1976, Rębiałkowska 1978).

For their development (May-September) beetles require fresh faeces (Sijazov 1913). Pellet samples placed on the forest floor before that period were too dry to attract the beetles, so they continued to exist in the habitat a long time. Faeces exposed after the activity period of the beetles were in the following year even less attractive, hence the autumn faeces persisted longer than those of early spring.

The different rates of faeces disappearance in a mixed coniferous forest and a mixed deciduous forest, with a slightly faster rate in the richer habitat, can be caused by different factors. Maybe they are the following: higher densities of coprophages in richer habitats (Borowski 1960), slightly different weather conditions in the near-ground forest layer, and probably a richer, quantitatively and qualitatively, level of reducers.

The number of the roe deer estimated in the present research on the basis of faeces analyses was compared with the data from an exact roe deer census carried out in the study area by herding. The census data indicated that there were in the forest at that time 108 roe deer (W. Aulak and J. Babińska-Werka, in prep.). The roe deer population size calculated on the basis of faeces analyses represented about $80 \%$ of that estimated by the direct census. The error amounted to about $20 \%$. However, observations carried out in the fields surrounding the forest under study indicated that about $50 \%$ of the roe deer remained in agrocoenoses for about 10 hours a day $(40 \%$ of a 24 -hour period) and defecated there. Therefore about $20 \%$ of pellets were left in the fields. In larger forest complexes, where a smaller number of roe deer move into fields, the error would probably be much smaller.

Thus, the numbers of roe deer estimated on the basis of faeces analyses and exact censuses appeared to be similar. The possibility of using the faeces analysis method for estimating the density of ugulates has been confirmed also by Riney (1957), Julander $\mathrm{et}$ al. (1963), Jurgenson (1970). The latter author found that the error of the method based on faeces analyses did not exceed $10 \%$. The estimation of roe deer population size by various authors was based primarily on winter states of faeces, whereas the method used in the present study makes it possible to determine the abundance of a population at any time. 
Acknowledgments: The authors wish to thank Prof. R. Andrzejewski for his valuable comments during the preparation of the manuscript.

\section{References}

Aulak W. (in print) Runo lasów doświadczalnych SGGW jako potencjalna baza żerowa dla roślinożerców. Zeszyty Naukowe SGGW.

Aulak W. and Babiniska-Werka J. 1990. Preference of different habitats and age-clases of forest by roe deer. Acta theriol. 35: 291-301.

Aulak W. and Goszczyński J. 1986. An inventory of hoofed populations driven through entire forest complex. Wiad. ekol. 33: 403-413. [In Polish with English summary]

Borowski S. 1960. Geotrupes stercorosus (Sc.) (Coleoptera, Scarabaeidae) in Białowieża National Park. Fragm. Faun. 8: 337-365. [In Polish with English and Russian summaries]

Breymeyer A. 1974. Analysis of a sheep pasture ecosystem in the Pieniny Mountains (The Carpathians). IX. The role of coprophagus beetles (Coleoptera, Scarabaeidae) in the utilization of sheep dung. Ekol. pol. 22: $617-634$.

Collins W. B. and Urness P. J. 1981. Habitat preference of mule deer as rated by pellet-group distributions. J. Wildl. Manage. 45: 969-972.

Drożdż A. and Osiecki A. 1973. Intake and digestibility of natural foods by roe deer. Acta theriol. 18: 81 -91.

Dzięciołowski R. 1976. Roe deer census by pellet-group counts. Acta theriol. 21: 351 - 358.

Eberhardt L. and Van Etten R.C. 1956. Evaluation of the pellet-group counts as a deer census method. J. Wildl. Manage. 20: $70-74$.

Gusev A. A. and Guseva N. A. 1983. Učaste dikich kopytnych v rozloženii rastitel'nosti v ekosistemach lesostepi. Ekologija 6: 51-55.

Helle P. 1980. Food composition and feeding habits of the roe deer in winter in central Finland. Acta theriol. 25: $395-402$.

Julander O., Ferguson R.B. and Dealy J.E. 1963. Measure of animal range use by signs [In: Range research methods.]. U. S. Dep. Agric. For. Serv., Misc. Publ. 940: 102-108.

Jurgenson P. P. 1970. Census of winter game number by the method of pellet group count. Trans. IX Inter. Congr. Game Biologists, Moscov: 287-288.

Mitchell E., Rowe J. J., Ratcliffe P. and Hinge M. 1985. Defecation frequency in roe deer (Capreolus capreolus) in relation to the accumulation rates of faecal deposits. J. Zool., Lond. (A) 207: 1-7.

Nakamura Y. 1975. Decomposition of organic materials and soil fauna in pasture. 2. Disappearance of cow dung. Pedobiologia 15: 129-132.

Padajga V. I. and Marma B. B. 1979. O metodikie ocenki čislennosti evropejskoj kosuli po količestve defekacii. Ekologija 4: 101-103.

Rębiałkowska M. E. 1978. Rola Geotrupes stercorosus (Scriba) (Scarabaeidae, Coleoptera) w przeplywie energii i materii przez ekosystem. Ph. D. Thesis, Inst. Ekologii PAN: 1-38.

Riney R. 1957. The use of faeces counts in studies of several free-ranging mammals in New Zealand. N. Z. J. Sci. Techn. B. 38: 507-532.

Robinette W. L., Ferguson R. B. and Gashwiler J. S. 1958. Problems involved in the use of deer pellet-group counts. North Amer. Wildlife Conf. Trans. 23: 411-425.

Sandner H. 1976. Owady. Państw. Wyd. Nauk., Warszawa: 1-60.

Sijazov M. 1913. Zadaci žukov navoznikov. Ljubitel' prirody, Taszkient: 1-12.

Wallmo O. C., Jackson A. W., Hailey T. L. and Carlisle R. L. 1962. Influence of rain in the count of deer pellet groups. J. Wildl. Manage. 26: 50-55. 
Wigley T. B. and Johnson M. K. 1981. Disappearance rates for deer pellets in the southeast. J. Wildl. Manage. 45: 251-253.

Zyzner E. and Urness P. J. 1969. Qualitative identification of forage remnants in deer faces. J. Wildl. Manage. 33: 506-510.

Received 15 April 1986, accepted 11 November 1989. 